\title{
Potential role of methylxanthines as an adjuvant to COVID-19 treatment: A review of Pentoxifylline and caffeine as the case of any port in the storm
}

\author{
Faezeh Monji $^{1}$, Abrar Siddiquee ${ }^{2}$, and Farshad Hashemian ${ }^{1}$ \\ ${ }^{1}$ Faculty of Pharmacy, Tehran Medical Sciences, Islamic Azad University \\ ${ }^{2}$ Institute of Molecular and Cell Biology (IMCB), Agency for Science, Technology and \\ Research (ASTAR)
}

May 22, 2020

\begin{abstract}
COVID-19 pandemic presents an unprecedented challenge to identify effective drugs for treatment. Despite multiple clinical trials using different agents, there is still a lack of specific treatment for COVID-19. Having the possible role in suppressing inflammation, immune modulation, antiviral and improving respiratory symptoms, this review discusses the potential role of methylxanthine drugs like pentoxifylline and caffeine in the management of COVID-19 patients. COVID-19 pathogenesis for clinical features like severe pneumonia, acute lung injury (ALI) / acute respiratory distress syndrome (ARDS), and multi-organ failures are excessive inflammation, oxidation, and cytokine storm by the exaggerated immune response. Drugs like pentoxifylline have already shown improvement of the symptoms of ARDS and caffeine has been in clinical use for decades to treat apnea of prematurity (AOP) in preterm infants and improve respiratory function. Both pentoxifylline and caffeine are well-known anti-inflammatory and anti-oxidative molecules that have already shown to suppress Tumor Necrosis Factor (TNF- $\alpha$ ) as well as other inflammatory cytokines in pulmonary diseases, and this may be beneficial for better clinical outcomes in COVID-19 patients. Pentoxifylline enhances blood flow, improves microcirculation and tissue oxygenation, and caffeine also efficiently improves microcirculation, reduces cardiovascular disease, and an effective analgesic. There are significant shreds of evidence that proved the properties of pentoxifylline and caffeine against virus-related diseases as well. Along with the aforementioned evidences and high safety profiles, both pentoxifylline and caffeine offer a glimpse of considerations for future use as a potential adjuvant to COVID-19 treatment. However, additional clinical studies are required to confirm this speculation.
\end{abstract}

\begin{abstract}
Abbreviations
ARDS: Acute Respiratory Distress Syndrome; TNF: Tumour Necrosis Factor; CHF: Chronic Heart failure; PDE: phosphodiesterase; AOP: Apnea of Prematurity; ALI: Acute Lung Injury; IFN: Interferon; IL: interleukin; IP-10: Interferon-inducible Protein 10; MCP-1: Monocyte Chemoattractant Protein 1; HDAC: histone deacetylase; ROS: Reactive Oxygen Species; OxPL: Oxidized Phospholipid; TLR: Toll-like receptor;

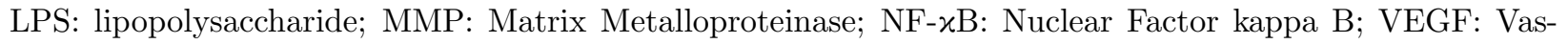
cular Endothelial Growth Factor; GCSF: Granulocyte Colony Stimulating Factor; cAMP: Cyclic adenosine 3',5'-monophosphate; PKA: Protein Kinase A; NLRP3: NOD-like receptor 3; MAPK: Mitogen-Activated Protein Kinase; ECMO: Extracorporeal Membrane Oxygenation; STAT: Signal Transducer and Activator of Transcription; BPD: bronchopulmonary dysplasia; TMPRSS2: Transmembrane protease serine 2; ACE: ACE: Angiotensin Converting Enzyme; CPE: Cytopathic effect.
\end{abstract}

\section{Introduction}

The severe acute respiratory syndrome coronavirus (SARS-CoV) are single-stranded positive-sense RNA 
viruses that cause severe respiratory diseases to the affected individuals (Cheng et al. 2007). In December 2019, a cluster of pneumonia cases emerged in Wuhan, China (Huang et al. 2020). This disease is now known as coronavirus disease 2019 (COVID-19) caused by the novel coronavirus now known as SARS-CoV-2 (severe acute respiratory syndrome coronavirus 2) that has spread globally, affecting a large portion of the human population across the world (Cohen and Normile 2020; Zhu et al. 2020).

The full range of symptoms for COVID-19 includes self-limiting respiratory tract illness to severe pneumonia, acute respiratory distress syndrome (ARDS), multi-organ failure, and death (Huang et al. 2020; Ruan et al. 2020a; Wang et al. 2020a). However, with time as the number of COVID-19 positive patients increase across the world, few neurological symptoms such as headache, paresthesia, and consciousness disorders were reported as well (Wu et al. 2020b). More recently, unusual manifestations of COVID19, including encephalitis, (Ye et al. 2020), acute necrotizing hemorrhagic encephalopathy (Poyiadji et al. 2020), and myocarditis (Doyen et al. 2020) have been documented. Besides, it has been noted that thrombotic complications in COVID-19 ICU patients increased remarkably (Klok et al. 2020). Lastly, skin manifestations like erythematous rash, urticaria, or chickenpox-like vesicles mainly in the body trunk in COVID-19 patients were reported in multiple studies (Joob and Wiwanitkit 2020; Recalcati 2020).

Therapeutic options to contain the COVID-19 pandemic is urgently needed. Favipiravir (T-705) (Wang et al. 2020b) and ribavirin have been evaluated on COVID-19 patients (ChiCTR2000029387), but ribavirin reported side effects (Zumla et al. 2016). Remdesivir (GS-5734) has been suggested (Al-Tawfiq et al. 2020; Cao et al. 2020b) and a compassionate-use remdesivir study showed $68 \%$ clinical improvement in COVID-19 patients (Grein et al. 2020). However, very recently, WHO reported controversy to the aforementioned data, and a full COVID-19 clinical trial of remdesivir was terminated due to the adverse side effects (unpublished report from WHO website). In addition, lopinavir-ritonavir treatment on COVID-19 patients did not show any improvement (Cao et al. 2020a). However, chloroquine, hydroxychloroquine (Gao et al. 2020; Gautret et al. 2020) and azithromycin with hydroxychloroquine showed potential clinical benefits but only in a limited number of COVID-19 patients (Gautret et al. 2020). Tocilizumab (Xu et al. 2020), as well as convalescent plasma therapy (Duan et al. 2020) in severely ill COVID-19 patients, also improved clinical outcomes, but inadequate clinical data to justify the observed effect. Although a range of the aforementioned therapies can be a near-term strategy to tackle COVID-19, there is still an evident lack of specific treatment for COVID-19 (Huang et al. 2020).

Methylxanthines are heterocyclic compounds that are methylated derivatives of xanthine comprising of coupled pyrimidinedione and imidazole rings (Talik et al. 2012). Methylxanthines have been widely used for therapeutic purposes for decades, with proven therapeutic benefits in different medical scopes. For example, the naturally occurring methylxanthines like caffeine, theophylline, and theobromine have been used in the treatment of respiratory diseases (Lam and Newhouse 1990), cardiovascular diseases (Batterman et al. 1959), cancer (HAYASHI et al. 2005; Kimura et al. 2009) and the commercially produced xanthine derivative drug like pentoxifylline has been widely documented to have immunomodulatory properties including the downregulation of Tumour Necrosis Factor (TNF) $\alpha$ to treat the injurious effects due to immune activation in the syndrome of chronic heart failure (CHF) (Shaw et al. 2009).

Pentoxifylline and its active metabolites enhance blood flow by decreasing blood viscosity and ameliorating erythrocyte flexibility. Administration of pentoxifylline produced hemorheological activity in a dosedependent manner. Based on the aforementioned mode of action, pentoxifylline has been approved to treat intermittent claudication due to chronic occlusive arterial disease of the limbs (Dettelbach and Aviado 1985). In these patients, pentoxifylline improves microcirculation and tissue oxygenation (Hsu et al. 1988; Harris et al. 2017). Pentoxifylline is also used for the management of alcoholic hepatitis (severe) (Whitfield et al. 2009) and venous leg ulcer off-label (Coccheri and Bignamini 2016; Zito and Murgia III 2018). Moreover, the effect of pentoxifylline has been demonstrated to treat fibrotic lesions by immunomodulation and by reducing inflammation (Wen et al. 2017).

Previous research has extensively established the effects of caffeine in the treatment of respiratory disease, its bronchodilatory effect via phosphodiesterase (PDE) inhibition, and adenosine receptor antagonism (Sullivan 
et al. 1994; Tilley 2011). Furthermore, caffeine is widely used to treat apnea of prematurity (AOP) in preterm infants by improving minute ventilation, $\mathrm{CO} 2$ sensitivity, respiratory muscle function, and neural respiratory drive. Caffeine administration also improved microcirculation in humans (Okuno et al. 2002), and moderate caffeine consumption was related to reduced coronary heart disease and stroke (Bøhn et al. 2012). Therapeutic indications of caffeine also include its role as the CNS stimulant to maintain seizure control during epilepsy (van Koert et al. 2018) as well as its role in treating headaches. As an adjuvant to analgesics, it enhances the efficacy of analgesics to treat headache (Lipton et al. 2017). Besides, the OTC labeling of caffeine is to restore mental alertness or wakefulness during fatigue (Childs and de Wit 2008). Despite the numerous benefits of caffeine, high doses of caffeine may lead to anxiety disorder (Lara 2010), and patients with an anxiety disorder are more sensitive to caffeine (Bruce et al. 1992).

Herein, we review with extensive evidence that widely used methylxanthines like caffeine and pentoxifylline may be used as an adjuvant therapy to treat COVID-19 induced respiratory symptoms by exploiting their reported immunomodulatory and anti-inflammatory potentials. Tissue oxygen levels have also been shown to be significantly increased by therapeutic doses of pentoxifylline in patients with peripheral arterial disease.

\section{COVID-19 pathogenesis and potential of methylxanthines use for therapeutic purpose}

Existing research recognizes the critical role played by "cytokine storm" in pathology associated with coronaviruses. It is now well established from a variety of studies; this condition is one of the primary underlying mechanism of the disease aggravation (Mehta et al. 2020). One of the very early publications about COVID19 reported a suppressed immune system followed by lymphopenia, neutropenia, hypo-albuminemia, as well as a decrease in CD8+ T cells (Chen et al. 2020). Further analysis of blood from COVID-19 patients showed high levels of inflammatory factors, including interleukin $1 \beta$ (IL-1 $\beta$ ), interferon $\gamma$ (IFN- $\gamma$ ), interferon-inducible protein 10 (IP-10), monocyte chemoattractant protein 1 (MCP-1), and also IL-4, IL-7, IL-8, IL-9, IL-10 and Tumour Necrosis Factor (TNF) $\alpha$ and overproduction of these inflammatory cytokines and chemokines may contribute to the progression of the disease (Huang et al. 2020). In SARS disease models, the cytokine storm associated disease pathology in Acute Lung Injury (ALI) was accompanied by increased expression of inflammatory genes (Channappanavar et al. 2016). Furthermore, decreasing the inflammatory monocytes/macrophages or ablation of the IFN- $\alpha / \beta$ receptor resulted in increased survival of the coronavirus host (Smits et al. 2010; Channappanavar et al. 2016). In both cases, a potential amplifying of the inflammation is involved underlying the $\mathrm{CoV}$ induced lung diseases. Hence, it could conceivably be hypothesized that cytokine storm, inflammation, and repressed immune function seemed to be a major feature in all COVID19 patients, and mitigation of disease progression may potentially be achieved by focusing the therapies on these major disease features.

Methylxanthines are well known as respiratory stimulants and used as one of the commonly used therapies for bronchial asthma. Methylxanthines are a unique class of drugs prescribed for asthmatic lung in humans because of their role in reversing the airflow obstruction and reducing airway hyperresponsiveness and airway inflammation. Methylxanthines also exert their effect via additional mechanisms, which include inhibition of immune cell activation, reduction of proinflammatory gene expression via induction of the histone deacetylase (HDAC) activity, and also via its effect on mucociliary transport (Tilley 2011). Methylxanthines have shown to lower allergic inflammations in several species like rats, rabbits, and guinea pigs (Pauwels 1987; Ali et al. 1992; Manzini et al. 1993). The anti-inflammatory properties of methylxanthines were eventually established in a series of clinical studies that showed a significant decrease in EG2+ eosinophils (which correlates to decreased airway inflammation during asthma), reduction of CD4+ lymphocytes in the bronchial wall (Sullivan et al. 1994). Ever since, methylxanthines have been efficiently used therapeutically for respiratory diseases. 


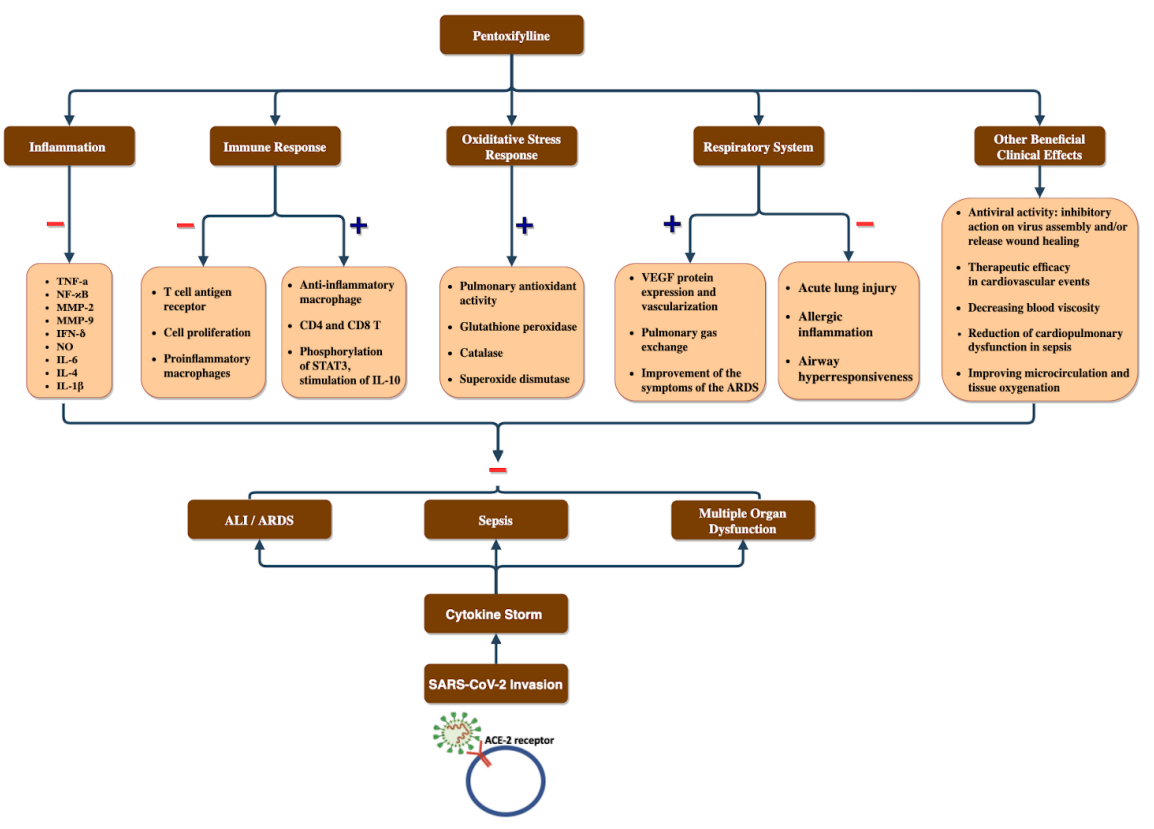

Figure 1. Overview of the potential adjuvant use of pentoxifylline in relation to COVID-19 clinical manifestations. We postulated that cytokine storm results after the SARS-CoV-2 invasion resulting in COVID-19 symptoms like ALI/ARDS, sepsis and multiple organ disorders which can potentially be prevented by pentoxifylline via its inhibitory effect on inflammatory cytokines, proinflammatory immune cells, and ALI as well as its stimulatory effect on anti-inflammatory macrophages, IL-10, pulmonary anti-oxidant enzymes and gas exchange as well as efficacy in cardiovascular events and against viruses. ALI: Acute lung injury; ARDS: Acute respiratory distress syndrome, IL-10: Interleukin-10.



Figure 2. Outline of caffeine as a potential adjuvant therapy for COVID-19 in relation to COVID-19 clinical 
manifestations. We proposed anti-inflammatory effect of caffeine on SARS-CoV-2 mediated inflammation. In addition, caffeine also has the potential to significantly inhibit the NLRP-3 inflammasome, proinflammatory macrophages, as well as BPD and AOP in infants. Caffeine also have positive effects on CD8+ $\mathrm{T}$ cells, cytotoxic $\mathrm{T}$ cells, total lymphocytes and stimulatory effect on myeloperoxidase, improved asthma, lung function, ARDS as well as microcirculation, antiviral activity, reduced fibrosis and coronary diseases. NLRP3: NOD-like receptor 3, BPD: Bronchopulmonary dysplasia, AOP: Apnea of prematurity, ARDS: Acute respiratory distress syndrome.

\section{Pentoxifylline and Caffeine as a potential anti-inflammatory and antioxidant agent for COVID- 19}

Viral infections, in general, are associated with the constant generation of oxidized products. Previously it has been shown that viral lung pathogens can trigger the oxidative stress pathways resulting in the generation of ROS as well as local production of oxidized phospholipid (OxPL) (Imai et al. 2008). Analysis of humans died in SARS-CoV infections showed the massive formation of OxPLs in all the severe cases of acute lung injury (ALI) (Imai et al. 2008). In a disease model, it was shown that ALI was caused by the overproduction of IL-6 in alveolar macrophages via Toll-like receptor 4 (TLR4)/NF-kB signaling and it was a result of the activated innate immune response due to the SARS-CoV induced production of OxPLs (Imai et al. 2008). In addition to the challenge of ALI due to SARS-CoV, severe acute respiratory distress syndrome (ARDS) treatment is an ongoing challenge for COVID-19 patients infected with SARS-CoV-2 (Matthay et al. 2020). Patients with severe cases of ALI/ARDS are treated in intensive care units (ICUs) and have severe inflammation. Several factors contribute to the inflammation, including hypoxia, due to inflammatory mediators like cytokines and viral infection (Sarma and Ward 2011). Accordingly, we speculate that similar excessive oxidation is likely to be involved in COVID-19 patients. This speculation was further supported by the severe inflammatory response observed in COVID-19 patients with heightened levels of the proinflammatory cytokines like IL-2, IL-4, IL-7, IL-8, IL-9 and also high amounts of IL-1 $\beta$, IFN $\gamma$, IP-10, and MCP-1, which probably points towards an activated T-helper-1 (Th1) cell responses (Huang et al. 2020).

\section{Pentoxifylline:}

Prior studies have reported that alveolar macrophages release inflammatory cytokines such as TNF- $\alpha$ that plays an important role in the prognosis of inflammatory pulmonary diseases (Kelley 1990; Sibille and Reynolds 1990). Consistent with the literature, it has been shown that pentoxifylline elicited a significant reduction in the production of TNF- $\alpha$ in cultured cells of LPS -stimulated alveolar macrophages and peripheral blood monocytes isolated from patients with an indication for bronchoalveolar lavage (Poulakis et al. 1999). This finding was also reported by Tong et al. (Tong et al. 2003). The results of this study indicate that pentoxifylline suppressed TNF- $\alpha$ production in a dose-dependent manner in alveolar macrophages in sarcoidosis, which is mainly driven by proinflammatory and anti-inflammatory mediators. Data from another study demonstrated that pentoxifylline suppressed cytokine-induced neutrophil chemoattractant, nuclear factor kappa B (NF- $\varkappa$ B), Matrix metalloproteinase-2 (MMP-2), MMP-9 and myeloperoxidase content in Sprague Dawley rat model (Deree et al. 2007). As mentioned in the literature review, MMPs are well-known inflammatory mediators that contribute to the aggravation of ALI and ARDS by accelerating the secretion of neutrophils into the lung (Torii et al. 1997; Corbel et al. 2000). This action is correlated with the proteolytic activity of MMPs.

The efficacy of pentoxifylline in improving the survival rate during hyperoxia has been shown in neonatal rats (Almario et al. 2012). Shreds of evidence suggested that pentoxifylline enhanced the pulmonary antioxidant activity in enzymes such as glutathione peroxidase, catalase, and superoxide dismutase. Another important finding was that pentoxifylline treatment enhanced vascularization through increasing the vascular endothelial growth factor (VEGF) protein expression (Almario et al. 2012). It is well established that VEGF involved in alveolar structures (Thébaud and Abman 2007). Subsequently, it has been shown that pentoxifylline not only suppresses proinflammatory macrophages but also enhances both wound healing and anti-inflammatory macrophage in nitrogen mustard -induced lung injury and inflammation (Sunil et al. 2014). Clinical trial in patients with acute coronary syndromes has shown the meaningful reduction in 
pro-inflammatory and elevation of the anti-inflammatory response following administration of pentoxifylline $400 \mathrm{mg}$ TDS for 6 months. These results suggest the potential therapeutic efficacy of pentoxifylline in cardiovascular events (Fernandes et al. 2008).

Considering the extensive evidence on anti-inflammatory and antioxidant properties of pentoxifylline (Figure 1), this molecule may have beneficial clinical effects in COVID-19 patients suffering from the severe inflammatory response.

\section{Caffeine:}

Following the previously published preclinical studies, caffeine showed anti-inflammatory effects in the lungs of rat pups following its administration at a low neonatal dose (Köroğlu et al. 2014). Further preclinical studies showed that caffeine reduced the production of proinflammatory cytokines in a rat model of endotoxic shock (Tofovic et al. 2001) and also suppressed the TNF- $\alpha$-induced apoptosis and hepatitis in mice model (Sugiyama et al. 2001). Besides, it was also reported in another preclinical study that acute caffeine treatment at a high dose or chronic caffeine treatment at a low dose reduced lung damage and inflammatory cytokines like TNF- $\alpha$ and IL-1 levels in a lung injury mice model. However, a chronic caffeine treatment at a low dose enhanced inflammation and lung damage ( $\mathrm{Li}$ et al. 2011). On a similar note, in vitro studies showed the presence of coffee extracts on lipopolysaccharide (LPS)-treated murine macrophage-like cells showed a decrease in mRNA levels of TNF- $\alpha$ and IL-6 (Jung et al. 2017). Such an anti-inflammatory effect of caffeine correlates with reduced expression of IL-6, IL-3, and IL-12 by LPS-treated murine macrophage cells (Samieirad et al. 2017). In another study, 50uM caffeine treatment on LPS-activated cord blood (neonatal) monocytes showed a $20 \%$ decrease of TNF- $\alpha$ production (Chavez-Valdez et al. 2009) and at a concentration of $100 \mu \mathrm{M}$ caffeine suppressed the TNF- $\alpha$ production by LPS-stimulated human whole blood by approximately $40 \%$ (Horrigan et al. 2004). In addition to preclinical and in vitro data, there is epidemiological evidence showing that caffeine intake as a protective factor for diseases like Alzheimer's disease (Maia and De Mendonça 2002). The neuroprotective effects could be due to its anti-inflammatory properties. The extensive studies showing anti-inflammatory and anti-oxidative properties of caffeine(Figure 2) suggests that it may play a potential therapeutic role and a possible treatment of inflammation and oxidations in COVID-19 patients.

\section{Pentoxifylline and Caffeine as potential immunomodulatory agent for COVID-19 treatment}

It is well established that following the entrance of respiratory viruses into the epithelial cell of the lung, the viral antigen will be presented on the cell surface to the cytotoxic CD8+ T cells. These cells are capable of killing infected cells by releasing the proinflammatory cytokines, including IFN $\gamma$ (Rogers and Williams 2018). Although this process is vital for clearing viral infections, complications can occur as it interferes with uninfected cells as well as lung function. In severe cases, cytotoxic CD8+ T cells and high concentration of the cytokines may cause serious injury to the lung (Bauer et al. 2006).

Amplification of the inflammatory signaling cascade can affect vascular permeability through an increasing influx of more phagocytes such as neutrophils and macrophages, leading to vascular endothelium dysfunction (Sharp et al. 2015). Due to this damage, the capacity of ventilation and gas exchange can be reduced drastically. Consequently, the patient may develop acute respiratory failure and require critical care support (Yang et al. 2018).

Moreover, it was also reported that patients with severe COVID-19 cases in ICU showed high levels of IP10, MCP1, GCSF, and TNF $\alpha$ than non-severe COVID-19 patients, suggesting a possible cytokine storm behind the severity of COVID-19 (Huang et al. 2020). Methylxanthines are known to have immune-modulatory effects at low serum concentration and, therefore can be potentially exploited as immunomodulators (Tilley 2011).

\section{Pentoxifylline:}

There is a growing body of literature that recognizes various activities of pentoxifylline on immune cells (Figure 1). The immunomodulatory effect of this molecule has been studied extensively in both animal 
models and human clinical trials.

The anti-apoptotic activity of pentoxifylline has been demonstrated in human cell lines (Gupta et al. 1999). Pentoxifylline increases immune memory in CD4 and CD8 T cells by suppressing the activation of mediated $\mathrm{T}$ cell apoptosis, which is attributed to the cAMP-PKA-mediated pathway (Suresh et al. 2002). Besides, pentoxifylline was able to attenuate the apoptosis induced by TNF- $\alpha$, IFN- $\delta$, and nitric oxide (NO) (MensahBrown et al. 2002). In a randomized, double-blind, controlled clinical trial, pentoxifylline significantly decreased the serum concentrations of TNF $\alpha$ and IL-6 (González-Espinoza et al. 2012). IL-6 is a mortality predictor of COVID-19 patients (Ruan et al. 2020b), and in severely affected COVID-19 patients, IL-6 levels are increased (Qin et al. 2020). Therefore, the idea of pentoxifylline to significantly bring down IL-6 levels to dampen the cytokine storm in COVID -19 patients is captivating. As mentioned earlier, due to the high level of cytokines and risks of apoptosis of epithelial and endothelial cells along with the infected cells, pentoxifylline may propose a safer therapeutic option in COVID-19 patients.

Furthermore, pentoxifylline suppressed the expression of surface T cell antigen, including CD25, CD69, and CD98. In line with this study, it has been shown that pentoxifylline interferes with $\mathrm{T}$ cell proliferation via the CD3/T-cell receptor complex (González-Amaro et al. 1998). Further immunomodulatory activity of pentoxifylline has been shown in animal models. In a murine model, pentoxifylline administration reduced the airway hyperresponsiveness due to Th1 cytokine IFN $\delta$ (Fleming et al. 2001). In line with aforementioned study, the reversal of arthritic changes and attenuation of the Th1 (IFN- $\delta$ ) and Th2 (IL-4) cytokine have been also observed in a rheumatoid arthritis rat model following administration of pentoxifylline (Pal et al. 2016).

Elevated levels of Th1 and Th2 cytokines have been found in SARS-CoV patients (Josset et al. 2013), and Th1, as well as Th17, was reported to contribute to the cytokine storm in SARS-CoV-2 induced pulmonary viral infection ( Wu et al. 2020a). Therefore, the attenuating impact of pentoxifylline on Th1 and Th2 cytokine levels can be utilized for its potential role in COVID-19 patients.

There is emerging evidence showing the beneficial effects of pentoxifylline in chronic heart failure due to its immunomodulatory effects and suppression of $\mathrm{TNF} \alpha$ (Shaw et al. 2009). In addition to that, it has been described that pentoxifylline contributes to the suppression of TNF $\alpha$ and IL- $1 \beta$ induced by Toll-like receptors (TLRs). This suppression role of TNF $\alpha$ and IL-1 $\beta$ by pentoxifylline can be exploited as a therapeutic potential because in COVID-19 patients, as SARS-CoV-2 also induces lung inflammation, fever, and fibrosis by inducing active production of TNF $\alpha$ and IL-1 $\beta$ (Conti et al. 2020). TNF $\alpha$ has always been involved in SARS-CoV induced severe immune-based pulmonary injury, which suggests that TNF $\alpha$ inhibitors could be a potential treatment for the respiratory symptoms caused by the coronavirus (Tobinick and opinion 2004). Collecting the aforementioned evidence regarding the immunomodulatory activity of pentoxifylline suggests a potential therapeutic value of this agent in COVID-19 patients.

\section{Caffeine:}

Various studies have demonstrated that caffeine can modulate different aspects of innate and adaptive immunity. Caffeine has been shown to affect cytokine production, free radical production, lymphocyte proliferation, antibody production, natural killer cell function, histamine release, and immune cell apoptosis (Horrigan et al. 2006). Myeloperoxidases are essential for the antimicrobial activity during neutrophil's respiratory burst, and in vitro studies showed that caffeine significantly increases the release of myeloperoxidase from a mixed population of neutrophils and PBMC (Sullivan et al. 1995). As a reduction of neutrophils was observed in the peripheral blood of COVID-19 patients (Liu et al. 2020), the enhancement of myeloperoxidase activity by caffeine could potentially improve COVID-19 disease condition. In line with caffeine's role in immunomodulation, an intriguing study reported that a bolus dose of $6 \mathrm{mg} / \mathrm{kg}$ caffeine caused an increase in total lymphocyte count and an increase in CD8+ T cell count (Bishop et al. 2005). The same study also reported that an increase of $\mathrm{CD} 4+\mathrm{CD} 69+\mathrm{T}$ cells before and after exercise with pre-exercise caffeine ingestion only (Bishop et al. 2005). Therefore, it shows the immune stimulatory role of caffeine on T cells. Furthermore, a reduction in lymphocytes and CD8+ positive T cells in the peripheral blood of COVID-19 
patients (Liu et al. 2020) means that caffeine may have the potential to increase the CD8+ T cells as well as the other cytotoxic CD4+CD69+ T cells in these patients and alleviate COVID-19 related symptoms by immune modulation

\section{(Figure 2).}

During lung injury, the NOD-like receptor 3 (NLRP3) inflammasome plays a key role in the innate immune response (Wu et al. 2013). When macrophages sense external pathogens like LPS or viral particles (CoVs not tested yet), activated NLRP3 interacts with apoptosis-associated proteins to form the NLRP3 inflammasome and results in the secretion of the proinflammatory cytokines IL- $1 \beta$ and IL-18 in macrophages to amplify inflammation (Lamkanfi et al. 2012; Guo et al. 2015). NLRP3 activity probably has a balance of protective and damaging action in the lung. It was reported that NLRP3 inhibition in an early infection mouse model increased mortality, but the suppression of NLRP3 at the peak of the infection showed a protective effect (Tate et al. 2016). This outcome supports the potential use of caffeine when COVID-19 related respiratory inflammation is most severe. Furthermore, caffeine was proven to significantly reduce NLRP3 expression and associated caspase cleavage and therefore suppressed the secretion of IL-1 $\beta$ and IL-18 in THP-1 macrophages (Zhao et al. 2019). In addition to that, caffeine was confirmed to inhibit NLRP3 inflammasome activation by suppressing the MAPK/NF- $x$ B signaling in THP-1 macrophages. NLRP1 inflammasome is correlated to lung diseases caused by influenza A virus, bacteria, and syncytial virus (Yang et al. 2006; Tate et al. 2016; Shen et al. 2020). Along with the aforementioned compelling evidence, we propose a potential immunomodulatory role of caffeine in COVID-19 related respiratory inflammation.

\section{Pentoxifylline and Caffeine as a potential adjuvant therapy for COVID-19 related respiratory symptoms}

The respiratory clinical manifestations of patients with SARS-CoV-2 range from pneumonia, dyspnea, rhinorrhea, upper airway congestion, cough, and pharyngalgia (Lai et al. 2020). In severe cases, death may result due to colossal alveolar damage and progressive respiratory failure (Chan et al. 2020). The main feature of COVID-19 patients with severe disease is the acute onset of hypoxemic respiratory failure with bilateral infiltrates known more commonly as Acute Respiratory Distress Syndrome (ARDS) (Murthy et al. 2020). For the COVID-19 patients with ARDS, extracorporeal membrane oxygenation (ECMO) is recommended (Matthay et al. 2020). However, this process of ECMO is invasive and comes with practical constraints that accompany intubation and mechanical ventilation. For the less severe COVID-19 related respiratory symptoms where mechanical ventilation is not required, alternative evidence-based treatment options can be considered.

\section{Pentoxifylline:}

Preliminary randomized clinical trial on pentoxifylline (400 mg, TDS for 12 weeks) demonstrated the enhancement of pulmonary gas exchange in COPD patients. A possible mechanism for these results could have been by the increase in the cardiac output and mixed venous $\mathrm{pO}_{2}$ (Haas et al. 1990). A subsequent trial on severe ARDS has shown that administration of pentoxifylline with a dose of $100 \mathrm{mg}$ IV BD for seven days, followed by $400 \mathrm{mg}$ PO TDS, led to the improvement of the symptoms of the ARDS, suppression of mean TNF levels and increasing the survival rate (Montravers et al. 1993).

Furthermore, the efficacy of pentoxifylline in attenuation of acute lung injury has been shown in animal models such as guinea pigs (Lilly et al. 1989). It is also well established that the administration of pentoxifylline at the time of allergen sensitization airway hyperresponsiveness suppresses the allergic inflammation and airway hyperresponsiveness in vivo (Fleming et al. 2001). The observed bronchodilatory, anti-inflammatory, and immunomodulatory properties provide further support for suggesting the pentoxifylline as a promising medicine in severe acute respiratory syndrome (SARS) (Martín et al. 2003).

In a more recent study, pentoxifylline treatment improved ALI-induced by Infrarenal aortic cross-clamping in the Wistar rat model. The proposed mechanism involved the phosphorylation of STAT3, leading to the stimulation of IL-10 production ( $\mathrm{Li}$ et al. 2016). The beneficial effect of pentoxifylline on lung has been 
demonstrated in lung cancer patients. A combination of pentoxifylline and vitamin E decreased radiationinduced lung toxicity frequency in lung cancer patients receiving concurrent chemo-radiotherapy (Misirlioglu et al. 2007). These results are in line with those that found the preventive efficacy of the combination, as mentioned earlier in the alleviation of some radiation-induced side-effects in patients with either breast (Magnusson et al. 2009) or head and neck cancer (Sayed et al. 2020). With the massive evidence of lung involvement in COVID-19 patients, pentoxifylline may offer a safe and well-tolerated option to treat the respiratory symptoms in these patients potentially (Figure 1) .

\section{Caffeine:}

Among the range of methylxanthines, caffeine is most commonly used for preterm infants with apnea receiving non-invasive respiratory support (Clark et al. 2006). Ventilating preterm infants may result in severe pulmonary adverse like bronchopulmonary dysplasia (BPD) (Moschino et al. 2020). Therefore, as non-invasive respiratory support, caffeine has already shown to reduce apnea of prematurity along with its associated improved lung function at 11 years of age (Jobe 2017). Caffeine treatment on preterm infants at birth also showed significant improvement in minute ventilation and tidal volume (Dekker et al. 2017) as well as extubation success (Henderson-Smart and Davis 2001). In addition to that, caffeine is also of the few known drugs shown to reduce the risk of BPD at 36 weeks post-menstrual age (PMA) (Dobson et al. 2014). These evidences suggest suggests a potential role of caffeine to treat the respiratory symptoms in infants with COVID-19 (Hong et al. 2020). Furthermore, caffeine showed asthma improvement in adults as well. It was reported that people with mild to moderate asthma improved lung function even at a low dose of $5 \mathrm{mg} / \mathrm{kg}$ body weight (Welsh et al. 2010). Caffeine also showed a significant bronchodilator effect in young patients with asthma (Becker et al. 1984). Among the various proposed mechanisms for the bronchodilator effect, the most well-established mechanism Phosphodiesterase (PDE) inhibition and adenosine receptor antagonism (Tilley 2011). Along with the well-established role in improving pulmonary functions and respiratory symptoms as well as its bronchodilatory role on the upper respiratory tract of patients (Figure 2), caffeine makes itself a compelling candidate as an adjuvant therapy for COVID-19 patients showing respiratory symptoms.

\section{Potential Antiviral activity of Pentoxifylline and Caffeine for COVID-19 treatment}

The spike (S) protein of coronaviruses (CoV ) allows viral entry to the target cells (Hoffmann et al. 2020). $\mathrm{CoV} \mathrm{S}$ protein is an essential component in determining the virulence of the virus, tissue tropism, and host range. The SARS-S protein uses angiotensin-converting enzyme 2 (ACE 2) as the entry receptor (Li et al. 2003), and the cellular serine protease TMPRSS2 carries out the S-protein priming and activation (Shulla et al. 2011). SARS-S protein of SARS-CoV and SARS-2-S protein of SARS-CoV-2 share about $76 \%$ amino acid identity. Following the previous results, a recent study showed compelling evidence that the entry of SARS$\mathrm{CoV}-2$ also depends on the ACE 2 receptor, and this entry can be blocked by serine protease TMPRSS2 inhibitor (Hoffmann et al. 2020). Similarly, another study also reported SARS-CoV-2-S protein entry on 293/hACE2 cells is mainly mediated by endocytosis (Ou et al. 2020). Following its entry, the virus expresses the genes encoding all structural and accessory proteins by adopting the genome of their host. The viral nucleocapsids are assembled in the cytoplasm, enter into the lumen of the endoplasmic reticulum (Graham and Baric 2010). Subsequently, virions will be released through the process of exocytosis. They can infect various cells, including $\mathrm{T}$ lymphocytes, as well as organs like the liver, kidney, and the lower respiratory tract (Tynell et al. 2016). Therefore, they can provide potential drug targets, and also antibody raised against SARS-CoV could at least partly protect against SARS-CoV-2 infection and both the serine protease TMPRSS2 and the ACE 2 could be a possible target for therapeutic intervention (Hoffmann et al. 2020).

Broad-spectrum antiviral drugs such as IFN-alpha, protease inhibitors like the lopinavir, nucleoside analogs, including ribavirin, and Neuraminidase inhibitors such as remdesivir can be used as a potential antiviral treatment for the coronavirus infected patients via interfering at different stages of the viral replication cycle. However, there is a lack of enough clinical data and direct evidence in COVID-19 patients are yet to be studied.

\section{Pentoxifylline:}


The antiviral property of pentoxifylline against tick-borne encephalitis virus, herpes simplex virus, vaccinia virus, and rotavirus has been shown in vitro, indicating the wide-spectrum of antiviral activity of pentoxifylline (Amvros' eva et al. 1993). This also accords with the previous report, which demonstrated the suppression of the human immunodeficiency virus type 1 replication in human peripheral blood mononuclear cells (Fazely et al. 1991). Furthermore, in a randomized, controlled trial, adjunctive therapy with pentoxifylline in HIV patients with tuberculosis resulted in a statistically significant overall reduction in plasma HIV RNA compared to the control group (Wallis et al. 1996). The evaluation of pentoxifylline in HIV patients demonstrated a transient positive trend of change in CD4+ and CD8+ cells (Clerici et al. 1997)

There are limited, precise details on the antiviral mechanism of pentoxifylline. Concerning this question, research has been done to identify the stage at which pentoxifylline inhibits the replication of the Japanese encephalitis virus. The finding of this study provides further support for the hypothesis that the drug most likely exerted its inhibitory action on virus assembly and/or release (Sebastian et al. 2009) and, therefore, may have the potential to use a similar inhibitory effect(Figure 1) on SARS-CoV-2 virus as well.

\section{Caffeine:}

Preliminary reports showed caffeine as a potential antiviral agent with its antiviral effect on certain viruses like the influenza virus, poliovirus, herpes simplex virus type 1 (HSV-1), and vaccinia virus (Yamazaki and Tagaya 1980). Subsequent studies showed that caffeine also inhibited viral RNA synthesis and viral protein synthesis in infected cells and thereby inhibiting growth and propagation of Newcastle disease virus (NDV), HSV-1, human immunodeficiency virus, vaccinia virus and polyomavirus (Olson and Consigli 1979; Shiraki and Rapp 1988; Dahl et al. 2005; Daniel et al. 2005). Caffeine was reported to inhibit the protein synthesis of HSV-1, which suppressed the formation of HSV-1 plaques by interfering with the cell-cell transmission of HSV-1 (Shiraki and Rapp 1988). Later it was further confirmed by the quantitative characterization that caffeine preferentially causes cytopathic effect (CPE) and the death of HSV-1 infected cells (Murayama et al. 2008). Therefore, such preferential CPE of caffeine on virally infected cells raises the potential of SARS-CoV-2 infected patient cells as caffeine could potentially reduce the viral load and also could induce selective death of virus-infected cells of COVID-19 patients. However, it is very important to note that caffeine-induced increased CPE and cell death was not detected for influenza virus and poliovirus and this was probably because these two viruses generally induced rapid cell death of infected cells immediately after infection and therefore masked the acceleration of caffeine-induced CPE of virus-infected cells if any (Murayama et al. 2008).

The aforementioned observation suggests that caffeine-induced selective degeneration of virally infected cells may be dependent on the species of the virus. In a more recent meta-analysis on the effect of caffeine in patients with chronic hepatitis $\mathrm{C}$, it was shown that patients with higher caffeine intake showed $61 \%$ reduced risk of developing advanced hepatic fibrosis and was also associated with lower serum ALT levels in chronic hepatitis C patients compared to lower caffeine intake patient group (Jaruvongvanich et al. 2017). Specifically for hepatitis $\mathrm{C}$, an in-vitro study also demonstrated that caffeine efficiently inhibited the replication of hepatitis $\mathrm{C}$ replication in a dose-dependent manner, further confirming the antiviral potential of caffeine (Batista et al. 2015). Overall, there is compelling evidence for the broad-spectrum antiviral role of caffeine, and its antiviral actions are well characterized in several viral species, and it could play a critical role in being a potential antiviral therapy in COVID-19 patients as well

\section{Conclusion}

The world has faced a new pandemic that has no proven pharmacotherapy despite all the attempts to develop a new effective medicine or vaccine with an acceptable safety profile. The current review has provided a collective data on the potential beneficial properties of methylxanthines like pentoxifylline and caffeine as an adjuvant therapy to treat COVID-19 patients. Addressing the broad spectrum of COVID19 symptoms including respiratory failure due to hypersensitivity and exaggerated immune response, is challenging. Pentoxifylline and caffeine with extensively proven therapeutic properties like anti-inflammatory, 
antioxidant, immunomodulatory, antiviral, as well as their beneficial effects in the alleviation of respiratory symptoms can be considered as an adjuvant treatment in COVID-19 patients. Moreover, pentoxifylline can also address the treatment of thrombotic complications, a recently identified manifestation of COVID-19. Although direct evidence of pentoxifylline and caffeine in COVID-19 patients are yet to be studied and also possible side effects should be considered, the insights gained from this review highlighted their efficacy and safety in COVID-19 and can be used to develop additional strategies to tackle this global challenge.

\section{References}

Al-Tawfiq, J. A., Al-Homoud, A. H. and Memish, Z. A. (2020) Remdesivir as a possible therapeutic option for the COVID-19. Travel medicine and infectious disease , 101615-101615.

Ali, S., Mustafa, S., Metzger, W. J. A. and actions (1992) Adenosine-induced bronchoconstriction in an allergic rabbit model: antagonism by theophylline aerosol. 37 (3-4), 165-167.

Almario, B., Wu, S., Peng, J., Alapati, D., Chen, S. and Sosenko, I. R. (2012) Pentoxifylline and prevention of hyperoxia-induced lung injury in neonatal rats.Pediatric research 71 (5), 583-589.

Amvros' eva, T., Votiakov, V., Andreeva, O., Vladyko, G., Nikolaeva, S., Orlova, S., Azarova, I. and Zgirovskaia, A. (1993) New properties of trental as an inhibitor of viral activity with a wide range of activity. Voprosy virusologii38 (5), 230-233.

Batista, M. N., Carneiro, B. M., Braga, A. C. S. and Rahal, P. J. A. o. v. (2015) Caffeine inhibits hepatitis $\mathrm{C}$ virus replication in vitro. 160 (2), 399-407.

Batterman, R., Grossman, A., Dubinsky, J., Mouratoff, G. J. I. r. o. m. and clinics, g. p. (1959) Reevaluation of the usefulness of theobromine calcium gluconate for the management of congestive heart failure and anginal syndrome. 172 (6), 318.

Bauer, T. T., Ewig, S., Rodloff, A. C. and Muller, E. E. (2006) Acute respiratory distress syndrome and pneumonia: a comprehensive review of clinical data. Clinical Infectious Diseases 43 (6), 748-756.

Becker, A. B., Simons, K. J., Gillespie, C. A. and Simons, F. E. R. (1984) The Bronchodilator Effects and Pharmacokinetics of Caffeine in Asthma. 310 (12), 743-746.

Bishop, N. C., Fitzgerald, C., Porter, P. J., Scanlon, G. A. and Smith, A. C. J. E. j. o. a. p. (2005) Effect of caffeine ingestion on lymphocyte counts and subset activation in vivo following strenuous cycling. 93 (5-6), 606-613.

Bohn, S. K., Ward, N. C., Hodgson, J. M. and Croft, K. D. (2012) Effects of tea and coffee on cardiovascular disease risk. Food \& Function 3 (6), 575-591.

Bruce, M., Scott, N., Shine, P. and Lader, M. J. A. o. G. P. (1992) Anxiogenic effects of caffeine in patients with anxiety disorders. 49 (11), 867-869.

Cao, B., Wang, Y., Wen, D., Liu, W., Wang, J., Fan, G., Ruan, L., Song, B., Cai, Y., Wei, M., Li, X., Xia, J., Chen, N., Xiang, J., Yu, T., Bai, T., Xie, X., Zhang, L., Li, C., Yuan, Y., Chen, H., Li, H., Huang, H., Tu, S., Gong, F., Liu, Y., Wei, Y., Dong, C., Zhou, F., Gu, X., Xu, J., Liu, Z., Zhang, Y., Li, H., Shang, L., Wang, K., Li, K., Zhou, X., Dong, X., Qu, Z., Lu, S., Hu, X., Ruan, S., Luo, S., Wu, J., Peng, L., Cheng, F., Pan, L., Zou, J., Jia, C., Wang, J., Liu, X., Wang, S., Wu, X., Ge, Q., He, J., Zhan, H., Qiu, F., Guo, L., Huang, C., Jaki, T., Hayden, F. G., Horby, P. W., Zhang, D. and Wang, C. (2020a) A Trial of Lopinavir-Ritonavir in Adults Hospitalized with Severe Covid-19.

Cao, Y. C., Deng, Q. X. and Dai, S. X. (2020b) Remdesivir for severe acute respiratory syndrome coronavirus 2 causing COVID-19: An evaluation of the evidence. Travel Med Infect Dis , 101647.

Chan, J. F.-W., Yuan, S., Kok, K.-H., To, K. K.-W., Chu, H., Yang, J., Xing, F., Liu, J., Yip, C. C.-Y., Poon, R. W.-S., Tsoi, H.-W., Lo, S. K.-F., Chan, K.-H., Poon, V. K.-M., Chan, W.-M., Ip, J. D., Cai, J.-P., Cheng, V. C.-C., Chen, H., Hui, C. K.-M. and Yuen, K.-Y. (2020) A familial cluster of pneumonia associated 
with the 2019 novel coronavirus indicating person-to-person transmission: a study of a family cluster. The Lancet 395 (10223), 514-523.

Channappanavar, R., Fehr, A. R., Vijay, R., Mack, M., Zhao, J., Meyerholz, D. K., Perlman, S. J. C. h. and microbe (2016) Dysregulated type I interferon and inflammatory monocyte-macrophage responses cause lethal pneumonia in SARS-CoV-infected mice. 19 (2), 181-193.

Chavez-Valdez, R., Wills-Karp, M., Ahlawat, R., Cristofalo, E. A., Nathan, A. and Gauda, E. B. J. P. r. (2009) Caffeine modulates TNF- $\alpha$ production by cord blood monocytes: the role of adenosine receptors. 65 (2), 203.

Chen, N., Zhou, M., Dong, X., Qu, J., Gong, F., Han, Y., Qiu, Y., Wang, J., Liu, Y. and Wei, Y. J. T. L. (2020) Epidemiological and clinical characteristics of 99 cases of 2019 novel coronavirus pneumonia in Wuhan, China: a descriptive study. 395 (10223), 507-513.

Cheng, V. C., Lau, S. K., Woo, P. C. and Yuen, K. Y. J. C. m. r. (2007) Severe acute respiratory syndrome coronavirus as an agent of emerging and reemerging infection. 20 (4), 660-694.

Childs, E. and de Wit, H. (2008) Enhanced mood and psychomotor performance by a caffeine-containing energy capsule in fatigued individuals. Experimental and Clinical Psychopharmacology 16 (1), 13.

Clark, R. H., Bloom, B. T., Spitzer, A. R. and Gerstmann, D. R. (2006) Reported medication use in the neonatal intensive care unit: data from a large national data set.Pediatrics 117 (6), 1979-87.

Clerici, M., Piconi, S., Balotta, C., Trabattoni, D., Capetti, A., Fusi, M. L., Ruzzante, S., Longhi, R., Colombo, M. C. and Moroni, M. (1997) Pentoxifylline improves cell-mediated immunity and reduces human immunodeficiency virus (HIV) plasma viremia in asymptomatic HIV-seropositive persons. Journal of Infectious Diseases 175 (5), 1210-1215.

Coccheri, S. and Bignamini, A. A. (2016) Pharmacological adjuncts for chronic venous ulcer healing. SAGE Publications Sage UK: London, England.

Cohen, J. and Normile, D. (2020)New SARS-like virus in China triggers alarm. American Association for the Advancement of Science.

Conti, P., Ronconi, G., Caraffa, A., Gallenga, C., Ross, R., Frydas, I., Kritas, S. J. J. o. b. r. and agents, h. (2020) Induction of pro-inflammatory cytokines (IL-1 and IL-6) and lung inflammation by Coronavirus-19 (COVI-19 or SARS-CoV-2): anti-inflammatory strategies. 34 (2).

Corbel, M., Boichot, E. and Lagente, V. (2000) Role of gelatinases MMP-2 and MMP-9 in tissue remodeling following acute lung injury. Brazilian Journal of Medical and Biological Research 33 (7), 749-754.

Dahl, J., You, J. and Benjamin, T. L. J. J. o. v. (2005) Induction and utilization of an ATM signaling pathway by polyomavirus. 79 (20), 13007-13017.

Daniel, R., Marusich, E., Argyris, E., Zhao, R. Y., Skalka, A. M. and Pomerantz, R. J. J. J. o. v. (2005) Caffeine inhibits human immunodeficiency virus type 1 transduction of nondividing cells. 79 (4), 2058-2065.

Dekker, J., Hooper, S. B., van Vonderen, J. J., Witlox, R. S., Lopriore, E. and Te Pas, A. B. J. P. r. (2017) Caffeine to improve breathing effort of preterm infants at birth: a randomized controlled trial. 82 (2), 290-296.

Deree, J., Martins, J., De Campos, T., Putnam, J. G., Loomis, W. H., Wolf, P. and Coimbra, R. (2007) Pentoxifylline attenuates lung injury and modulates transcription factor activity in hemorrhagic shock. Journal of Surgical Research 143 (1), 99-108.

Dettelbach, H. R. and Aviado, D. M. (1985) Clinical pharmacology of pentoxifylline with special reference to its hemorrheologic effect for the treatment of intermittent claudication. The Journal of Clinical Pharmacology $25(1), 8-26$. 
Dobson, N. R., Patel, R. M., Smith, P. B., Kuehn, D. R., Clark, J., Vyas-Read, S., Herring, A., Laughon, M. M., Carlton, D. and Hunt, C. E. J. T. J. o. p. (2014) Trends in caffeine use and association between clinical outcomes and timing of therapy in very low birth weight infants. 164 (5), 992-998. e3.

Doyen, D., Moceri, P., Ducreux, D. and Dellamonica, J. (2020) Myocarditis in a patient with COVID-19: a cause of raised troponin and ECG changes. Lancet .

Duan, K., Liu, B., Li, C., Zhang, H., Yu, T., Qu, J., Zhou, M., Chen, L., Meng, S., Hu, Y., Peng, C., Yuan, M., Huang, J., Wang, Z., Yu, J., Gao, X., Wang, D., Yu, X., Li, L., Zhang, J., Wu, X., Li, B., Xu, Y., Chen, W., Peng, Y., Hu, Y., Lin, L., Liu, X., Huang, S., Zhou, Z., Zhang, L., Wang, Y., Zhang, Z., Deng, K., Xia, Z., Gong, Q., Zhang, W., Zheng, X., Liu, Y., Yang, H., Zhou, D., Yu, D., Hou, J., Shi, Z., Chen, S., Chen, Z., Zhang, X. and Yang, X. (2020) Effectiveness of convalescent plasma therapy in severe COVID-19 patients. Proceedings of the National Academy of Sciences 117 (17), 9490.

Fazely, F., Dezube, B., Allen-Ryan, J., Pardee, A. and Ruprecht, R. (1991) Pentoxifylline (Trental) decreases the replication of the human immunodeficiency virus type 1 in human peripheral blood mononuclear cells and in cultured $\mathrm{T}$ cells [see comments].

Fernandes, J. L., de Oliveira, R. T. D., Mamoni, R. L., Coelho, O. R., Nicolau, J. C., Blotta, M. H. S. and Serrano Jr, C. V. (2008) Pentoxifylline reduces pro-inflammatory and increases anti-inflammatory activity in patients with coronary artery disease - a randomized placebo-controlled study. Atherosclerosis196 (1), 434-442.

Fleming, C. M., He, H., Ciota, A., Perkins, D. and Finn, P. W. (2001) Administration of pentoxifylline during allergen sensitization dissociates pulmonary allergic inflammation from airway hyperresponsiveness. The Journal of Immunology 167 (3), 1703-1711.

Gao, J., Tian, Z. and Yang, X. J. B. t. (2020) Breakthrough: Chloroquine phosphate has shown apparent efficacy in treatment of COVID-19 associated pneumonia in clinical studies.

Gautret, P., Lagier, J.-C., Parola, P., Meddeb, L., Mailhe, M., Doudier, B., Courjon, J., Giordanengo, V., Vieira, V. E. and Dupont, H. T. J. I. j. o. a. a. (2020) Hydroxychloroquine and azithromycin as a treatment of COVID-19: results of an open-label non-randomized clinical trial. 105949.

González-Amaro, R., Portales-Pérez, D., Baranda, L., Redondo, J. M., Martínez-Martínez, S., Yáñez-Mó, M., García-Vicuña, R., Cabañas, C. and Sánchez-Madrid, F. (1998) Pentoxifylline inhibits adhesion and activation of human T lymphocytes. The Journal of Immunology 161 (1), 65-72.

González-Espinoza, L., Rojas-Campos, E., Medina-Pérez, M., Peña-Quintero, P., Gómez-Navarro, B. and Cueto-Manzano, A. M. J. N. D. T. (2012) Pentoxifylline decreases serum levels of tumor necrosis factor alpha, interleukin 6 and C-reactive protein in hemodialysis patients: results of a randomized double-blind, controlled clinical trial. 27 (5), 2023-2028.

Graham, R. L. and Baric, R. S. (2010) Recombination, reservoirs, and the modular spike: mechanisms of coronavirus cross-species transmission. Journal of virology 84 (7), 3134-3146.

Grein, J., Ohmagari, N., Shin, D., Diaz, G., Asperges, E., Castagna, A., Feldt, T., Green, G., Green, M. L. and Lescure, F.-X. J. N. E. J. o. M. (2020) Compassionate use of remdesivir for patients with severe COVID-19.

Guo, H., Callaway, J. B. and Ting, J. P. J. N. m. (2015) Inflammasomes: mechanism of action, role in disease, and therapeutics. 21 (7), 677.

Gupta, M., George, A., Sen, R., Rath, S., Durdik, J. M. and Bal, V. (1999) Presence of pentoxifylline during $\mathrm{T}$ cell priming increases clonal frequencies in secondary proliferative responses and inhibits apoptosis. The Journal of Immunology 162 (2), 689-695. 
Haas, F., Bevelaqua, F., Levin, N., Solazar-Schicchi, J., Reggiani, J. L., Axen, K. and Pineda, H. (1990) Pentoxifylline improves pulmonary gas exchange. Chest 97 (3), 621-627.

Harris, S., Rasyid, A., Nurhayati, E. and Prihartono, J. (2017) Selected benefits of pentoxifylline in acute ischemic stroke management: consideration of risk factors. Health Science International Conference (HSIC 2017). Atlantis Press.

HAYASHI, M., TSUCHIYA, H., YAMAMOTO, N., KARITA, M., SHIRAI, T., NISHIDA, H., TAKEUCHI, A. and TOMITA, K. J. A. r. (2005) Caffeine-potentiated chemotherapy for metastatic carcinoma and lymphoma of bone and soft tissue. 25 (3C), 2399-2405.

Henderson-Smart, D. and Davis, P. J. T. C. L. (2001) Prophylactic methylxanthine for extubation in preterm infants (Cochrane Review). (4).

Hoffmann, M., Kleine-Weber, H., Schroeder, S., Krüger, N., Herrler, T., Erichsen, S., Schiergens, T. S., Herrler, G., Wu, N.-H. and Nitsche, A. J. C. (2020) SARS-CoV-2 cell entry depends on ACE2 and TMPRSS2 and is blocked by a clinically proven protease inhibitor.

Hong, H., Wang, Y., Chung, H. T. and Chen, C. J. (2020) Clinical characteristics of novel coronavirus disease 2019 (COVID-19) in newborns, infants and children. Pediatr Neonatol 61 (2), 131-132.

Horrigan, L. A., Kelly, J. P. and Connor, T. J. J. I. i. (2004) Caffeine suppresses TNF- $\alpha$ production via activation of the cyclic AMP/protein kinase A pathway. 4 (10-11), 1409-1417.

Horrigan, L. A., Kelly, J. P., Connor, T. J. J. P. and therapeutics (2006) Immunomodulatory effects of caffeine: friend or foe? 111 (3), 877-892.

Hsu, C. Y., Norris, J., Hogan, E., Bladin, P., Dinsdale, H., Yatsu, F., Earnest, M., Scheinberg, P., Caplan, L. and Karp, H. (1988) Pentoxifylline in acute nonhemorrhagic stroke. A randomized, placebo-controlled double-blind trial.Stroke 19 (6), 716-722.

Huang, C., Wang, Y., Li, X., Ren, L., Zhao, J., Hu, Y., Zhang, L., Fan, G., Xu, J. and Gu, X. (2020) Clinical features of patients infected with 2019 novel coronavirus in Wuhan, China. The Lancet 395 (10223), 497-506.

Imai, Y., Kuba, K., Neely, G. G., Yaghubian-Malhami, R., Perkmann, T., van Loo, G., Ermolaeva, M., Veldhuizen, R., Leung, Y. C. and Wang, H. J. C. (2008) Identification of oxidative stress and Toll-like receptor 4 signaling as a key pathway of acute lung injury. 133 (2), 235-249.

Jaruvongvanich, V., Sanguankeo, A., Klomjit, N., Upala, S. J. C., hepatology, r. i. and gastroenterology (2017) Effects of caffeine consumption in patients with chronic hepatitis C: A systematic review and metaanalysis. 41 (1), 46-55.

Jobe, A. H. (2017) Caffeine: A Lung Drug for All Very Low Birth Weight Preterm Infants? , American Thoracic Society.

Joob, B. and Wiwanitkit, V. (2020) COVID-19 can present with a rash and be mistaken for dengue. J Am Acad Dermatol 82 (5), e177.

Josset, L., Menachery, V. D., Gralinski, L. E., Agnihothram, S., Sova, P., Carter, V. S., Yount, B. L., Graham, R. L., Baric, R. S. and Katze, M. G. J. M. (2013) Cell host response to infection with novel human coronavirus EMC predicts potential antivirals and important differences with SARS coronavirus. 4 (3), e00165-13.

Jung, S., Kim, M. H., Park, J. H., Jeong, Y. and Ko, K. S. J. J. o. m. f. (2017) Cellular antioxidant and anti-inflammatory effects of coffee extracts with different roasting levels. 20 (6), 626-635.

Kelley, J. (1990) Cytokines of the lung. Am Rev Respir Dis 141 (3), 765-788. 
Kimura, H., Tsuchiya, H., Shirai, T., Nishida, H., Hayashi, K., Takeuchi, A., Ohnari, I. and Tomita, K. J. J. o. O. S. (2009) Caffeine-potentiated chemotherapy for metastatic osteosarcoma. 14 (5), 556-565.

Klok, F., Kruip, M., van der Meer, N., Arbous, M., Gommers, D., Kant, K., Kaptein, F., van Paassen, J., Stals, M. and Huisman, M. (2020) Incidence of thrombotic complications in critically ill ICU patients with COVID-19. Thrombosis Research .

Köroğlu, Ö. A., MacFarlane, P. M., Balan, K. V., Zenebe, W. J., Jafri, A., Martin, R. J. and Kc, P. J. N. (2014) Anti-inflammatory effect of caffeine is associated with improved lung function after lipopolysaccharideinduced amnionitis. 106 (3), 235-240.

Lai, C.-C., Shih, T.-P., Ko, W.-C., Tang, H.-J. and Hsueh, P.-R. (2020) Severe acute respiratory syndrome coronavirus 2 (SARS-CoV-2) and coronavirus disease-2019 (COVID-19): The epidemic and the challenges. International Journal of Antimicrobial Agents 55 (3), 105924.

Lam, A. and Newhouse, M. T. J. C. (1990) Management of asthma and chronic airflow limitation: are methylxanthines obsolete? 98 (1), 44-52.

Lamkanfi, M., Dixit, V. M. J. A. r. o. c. and biology, d. (2012) Inflammasomes and their roles in health and disease. 28, 137-161.

Lara, D. R. J. J. o. A. s. d. (2010) Caffeine, mental health, and psychiatric disorders. 20 (s1), S239-S248.

Li, H., Tan, G., Tong, L., Han, P., Zhang, F., Liu, B. and Sun, X. (2016) Pentoxifylline inhibits pulmonary inflammation induced by infrarenal aorticcross-clamping dependent of adenosine receptor A2A. American journal of translational research 8 (5), 2210.

Li, J., Li, G., Hu, J.-L., Fu, X.-H., Zeng, Y.-J., Zhou, Y.-G., Xiong, G., Yang, N., Dai, S.-S. and He, F.-T. J. E. j. o. p. (2011) Chronic or high dose acute caffeine treatment protects mice against oleic acid-induced acute lung injury via an adenosine A2A receptor-independent mechanism. 654 (3), 295-303.

Li, W., Moore, M. J., Vasilieva, N., Sui, J., Wong, S. K., Berne, M. A., Somasundaran, M., Sullivan, J. L., Luzuriaga, K. and Greenough, T. C. J. N. (2003) Angiotensin-converting enzyme 2 is a functional receptor for the SARS coronavirus. 426 (6965), 450-454.

Lilly, C. M., Sandhu, J. S., Ishizaka, A., Harada, H., Yonemaru, M., Larrick, J. W., Shi, T.-X., O'HANLEY, P. T. and Raffin, T. A. (1989) Pentoxifylline Prevents Tumor Necrosis Factor-induced Lung Injury1-3. Am Rev Respir Dis 139, 1361-1368.

Lipton, R. B., Diener, H. C., Robbins, M. S., Garas, S. Y. and Patel, K. (2017) Caffeine in the management of patients with headache. J Headache Pain 18 (1), 107.

Liu, Y., Yang, Y., Zhang, C., Huang, F., Wang, F., Yuan, J., Wang, Z., Li, J., Li, J. and Feng, C. J. S. C. L. S. (2020) Clinical and biochemical indexes from 2019-nCoV infected patients linked to viral loads and lung injury. 63 (3), 364-374.

Magnusson, M., Höglund, P., Johansson, K., Jönsson, C., Killander, F., Malmström, P., Weddig, A. and Kjellén, E. (2009) Pentoxifylline and vitamin E treatment for prevention of radiation-induced side-effects in women with breast cancer: a phase two, double-blind, placebo-controlled randomised clinical trial (Ptx5). European Journal of Cancer 45 (14), 2488-2495.

Maia, L. and De Mendonça, A. J. E. J. o. N. (2002) Does caffeine intake protect from Alzheimer's disease? $9(4), 377-382$.

Manzini, S., Perretti, F., Abelli, L., Evangelista, S., Seeds, E. A. and Page, C. P. J. E. j. o. p. (1993) Isbufylline, a new xanthine derivative, inhibits airway hyperresponsiveness and airway inflammation in guinea pigs. 249 (3), 251-257. 
Martín, J. F. B., Jiménez, J. L. and MuEóz-Fernández, A. (2003) Pentoxifylline and severe acute respiratory syndrome (SARS): a drug to be considered. Medical Science Monitor9 (6), SR29-SR34.

Matthay, M. A., Aldrich, J. M. and Gotts, J. E. J. T. L. R. M. (2020) Treatment for severe acute respiratory distress syndrome from COVID-19.

Mehta, P., McAuley, D. F., Brown, M., Sanchez, E., Tattersall, R. S. and Manson, J. J. (2020) COVID-19: consider cytokine storm syndromes and immunosuppression. The Lancet .

Mensah-Brown, E., Grujicic, S. S., Maksimovic, D., Jasima, A., Shahin, A. and Lukic, M. (2002) Downregulation of apoptosis in the target tissue prevents low-dose streptozotocin-induced autoimmune diabetes. Molecular immunology38 (12-13), 941-946.

Misirlioglu, C. H., Demirkasimoglu, T., Kucukplakci, B., Sanri, E. and Altundag, K. (2007) Pentoxifylline and alpha-tocopherol in prevention of radiation-induced lung toxicity in patients with lung cancer. Medical oncology $24(3), 308-311$.

Montravers, P., Fagon, J.-Y., Gilbert, C., Blanchet, F., Novara, A. and Chastre, J. (1993) Pilot study of cardiopulmonary risk from pentoxifylline in adult respiratory distress syndrome. Chest 103 (4), 1017-1022.

Moschino, L., Zivanovic, S., Hartley, C., Trevisanuto, D., Baraldi, E. and Roehr, C. C. J. E. O. R. (2020) Caffeine in preterm infants: where are we in 2020? 6 (1).

Murayama, M., Tsujimoto, K., Uozaki, M., Katsuyama, Y., Yamasaki, H., Utsunomiya, H. and Koyama, A. H. J. M. m. r. (2008) Effect of caffeine on the multiplication of DNA and RNA viruses. 1 (2), 251-255.

Murthy, S., Gomersall, C. D. and Fowler, R. A. (2020) Care for Critically Ill Patients With COVID-19.JAMA

Okuno, T., Sugiyama, T., Tominaga, M., Kojima, S. and Ikeda, T. (2002) Effects of Caffeine on Microcirculation of the Human Ocular Fundus. Japanese Journal of Ophthalmology 46 (2), 170-176.

Olson, N. and Consigli, R. J. A. j. o. v. r. (1979) Production of labile Newcastle disease virus progeny after infection of chicken embryo cells in the presence of caffeine. 40 (3), 387-392.

Ou, X., Liu, Y., Lei, X., Li, P., Mi, D., Ren, L., Guo, L., Guo, R., Chen, T. and Hu, J. J. N. C. (2020) Characterization of spike glycoprotein of SARS-CoV-2 on virus entry and its immune cross-reactivity with SARS-CoV. 11 (1), 1-12.

Pal, R., Chaudhary, M. J., Tiwari, P. C., Nath, R., Babu, S. and Pant, K. K. (2016) Pharmacological studies on the anti-inflammatory and immunomodulatory role of pentoxifylline and its interaction with nitric oxide (NO) in experimental arthritis in rats. Inflammopharmacology 24 (5), 221-231.

Pauwels, R. J. C. (1987) The effects of theophylline on airway inflammation. 92 (1), 32S-37S.

Poulakis, N., Androutsos, G., Kazi, D., Bastas, A., Provata, A., Bitsakou, C., Kontozoglou, T., Polyzogopoulou, C. and Tassiopoulou, A. (1999) The differential effect of pentoxifylline on cytokine production by alveolar macrophages and its clinical implications. Respiratory medicine 93 (1), 52-57.

Poyiadji, N., Shahin, G., Noujaim, D., Stone, M., Patel, S. and Griffith, B. (2020) COVID-19-associated acute hemorrhagic necrotizing encephalopathy: CT and MRI features.Radiology , 201187.

Qin, C., Zhou, L., Hu, Z., Zhang, S., Yang, S., Tao, Y., Xie, C., Ma, K., Shang, K. and Wang, W. J. C. I. D. (2020) Dysregulation of immune response in patients with COVID-19 in Wuhan, China.

Recalcati, S. (2020) Cutaneous manifestations in COVID-19: a first perspective. Journal of the European Academy of Dermatology and Venereology n/a (n/a).

Rogers, M. C. and Williams, J. V. (2018) Quis Custodiet Ipsos Custodes? Regulation of Cell-Mediated Immune Responses Following Viral Lung Infections. Annual review of virology 5, 363-383. 
Ruan, Q., Yang, K., Wang, W., Jiang, L. and Song, J. (2020a) Clinical predictors of mortality due to COVID-19 based on an analysis of data of 150 patients from Wuhan, China.Intensive care medicine, 1-3.

Ruan, Q., Yang, K., Wang, W., Jiang, L. and Song, J. J. I. c. m. (2020b) Clinical predictors of mortality due to COVID-19 based on an analysis of data of 150 patients from Wuhan, China. 1-3.

Samieirad, S., Afrasiabi, H., Tohidi, E., Qolizade, M., Shaban, B., Hashemipour, M. A. and Shirvan, I. D. J. J. o. C.-M. S. (2017) Evaluation of caffeine versus codeine for pain and swelling management after implant surgeries: A triple blind clinical trial. 45 (10), 1614-1621.

Sarma, J. V. and Ward, P. A. J. C. P. (2011) Oxidants and redox signaling in acute lung injury. 1 (3), $1365-1381$.

Sayed, R., El Wakeel, L., Saad, A. S., Kelany, M. and El-Hamamsy, M. (2020) Pentoxifylline and vitamin E reduce the severity of radiotherapy-induced oral mucositis and dysphagia in head and neck cancer patients: a randomized, controlled study. Medical Oncology 37 (1), 8.

Sebastian, L., Desai, A., Madhusudana, S. N. and Ravi, V. (2009) Pentoxifylline inhibits replication of Japanese encephalitis virus: a comparative study with ribavirin. International journal of antimicrobial agents $33(2), 168-173$.

Sharp, C., Millar, A. B. and Medford, A. R. (2015) Advances in understanding of the pathogenesis of acute respiratory distress syndrome. Respiration 89 (5), 420-434.

Shaw, S. M., Shah, M. K., Williams, S. G. and Fildes, J. E. J. E. j. o. h. f. (2009) Immunological mechanisms of pentoxifylline in chronic heart failure. 11 (2), 113-118.

Shen, C., Zhang, Z., Xie, T., Ji, J., Xu, J., Lin, L., Yan, J., Kang, A., Dai, Q. and Dong, Y. J. F. i. p. (2020) Rhein Suppresses Lung Inflammatory Injury Induced by Human Respiratory Syncytial Virus Through Inhibiting NLRP3 Inflammasome Activation via NF-xB Pathway in Mice. 10, 1600.

Shiraki, K. and Rapp, F. J. I. (1988) Effects of caffeine on herpes simplex virus. 29 (4), 235-240.

Shulla, A., Heald-Sargent, T., Subramanya, G., Zhao, J., Perlman, S. and Gallagher, T. J. J. o. v. (2011) A transmembrane serine protease is linked to the severe acute respiratory syndrome coronavirus receptor and activates virus entry. 85 (2), 873-882.

Sibille, Y. and Reynolds, H. Y. (1990) Macrophages and Polymorphonuclear neutrophils in lung defense and Injury1-2. Am Rev Respir Dis 141, 471-501.

Smits, S. L., de Lang, A., van den Brand, J. M., Leijten, L. M., van IJcken, W. F., Eijkemans, M. J., van Amerongen, G., Kuiken, T., Andeweg, A. C. and Osterhaus, A. D. J. P. p. (2010) Exacerbated innate host response to SARS-CoV in aged non-human primates. 6 (2).

Sugiyama, K., Noda, Y., He, P. J. B., biotechnology, and biochemistry (2001) Suppressive effect of caffeine on hepatitis and apoptosis induced by tumor necrosis factor- $\alpha$, but not by the anti-Fas antibody, in mice. 65 (3), 674-677.

Sullivan, G. W., Luong, L. S., Carper, H. T., Barnes, R. C. and Mandell, G. L. J. I. (1995) Methylxanthines with adenosine alter TNF $\boldsymbol{\alpha}$-primed PMN activation. 31 (1), 19-29.

Sullivan, P., Jaffar, Z., Page, C., Costello, J., Bekir, S. and Jeffery, P. J. T. L. (1994) Anti-inflammatory effects of low-dose oral theophylline in atopic asthma. 343 (8904), 1006-1008.

Sunil, V. R., Vayas, K. N., Cervelli, J. A., Malaviya, R., Hall, L., Massa, C. B., Gow, A. J., Laskin, J. D. and Laskin, D. L. (2014) Pentoxifylline attenuates nitrogen mustard-induced acute lung injury, oxidative stress and inflammation. Experimental and molecular pathology 97 (1), 89-98. 
Suresh, R., Vig, M., Bhatia, S., Goodspeed, E. P., John, B., Kandpal, U., Srivastava, S., George, A., Sen, R. and Bal, V. (2002) Pentoxifylline functions as an adjuvant in vivo to enhance T cell immune responses by inhibiting activation-induced death. The Journal of Immunology 169 (8), 4262-4272.

Talik, P., Krzek, J., Ekiert, R. J. S. and Reviews, P. (2012) Analytical techniques used for determination of methylxanthines and their analogues-Recent advances. 41 (1), 1-61.

Tate, M. D., Ong, J. D., Dowling, J. K., McAuley, J. L., Robertson, A. B., Latz, E., Drummond, G. R., Cooper, M. A., Hertzog, P. J. and Mansell, A. J. S. r. (2016) Reassessing the role of the NLRP3 inflammasome during pathogenic influenza A virus infection via temporal inhibition. 6, 27912.

Thébaud, B. and Abman, S. H. (2007) Bronchopulmonary dysplasia: where have all the vessels gone? Roles of angiogenic growth factors in chronic lung disease. American journal of respiratory and critical care medicine 175 (10), 978-985.

Tilley, S. L. (2011) Methylxanthines in Asthma. Methylxanthines. Berlin, Heidelberg: Springer Berlin Heidelberg. 439-456.

Tobinick, E. J. C. m. r. and opinion (2004) TNF-[alpha] inhibition for potential therapeutic modulation of SARS coronavirus infection. 20 (1), 39.

Tofovic, S. P., Zacharia, L., Carcillo, J. A. and Jackson, E. K. J. S. (2001) Inhibition of adenosine deaminase attenuates endotoxin-induced release of cytokines in vivo in rats. 16 (3), 196-202.

Tong, Z., Dai, H., Chen, B., Abdoh, Z., Guzman, J. and Costabel, U. (2003) Inhibition of cytokine release from alveolar macrophages in pulmonary sarcoidosis by pentoxifylline: comparison with dexamethasone. Chest 124 (4), 1526-1532.

Torii, K., Iida, K.-i., Miyazaki, Y., Saga, S., Kondoh, Y., Taniguchi, H., Taki, F., Takagi, K., Matsuyama, M. and Suzuki, R. (1997) Higher concentrations of matrix metalloproteinases in bronchoalveolar lavage fluid of patients with adult respiratory distress syndrome. American journal of respiratory and critical care medicine 155 (1), 43-46.

Tynell, J., Westenius, V., Rönkkö, E., Munster, V. J., Melén, K., Österlund, P. and Julkunen, I. (2016) Middle East respiratory syndrome coronavirus shows poor replication but significant induction of antiviral responses in human monocyte-derived macrophages and dendritic cells. The Journal of general virology 97 (Pt 2), 344 .

van Koert, R. R., Bauer, P. R., Schuitema, I., Sander, J. W. and Visser, G. H. (2018) Caffeine and seizures: A systematic review and quantitative analysis. Epilepsy Behav 80, 37-47.

Wallis, R., Nsubuga, P., Whalen, C., Mugerwa, R., Okwera, A., Oette, D., Jackson, J., Johnson, J. and Ellner, J. (1996) Pentoxifylline Therapy in Human Immunodeficiency Virus - Seropositive Persons with Tuberculosis: A Randomized, Controlled Trial. Journal of Infectious Diseases 174 (4), 727-733.

Wang, L., He, W., Yu, X., Hu, D., Bao, M., Liu, H., Zhou, J. and Jiang, H. (2020a) Coronavirus Disease 2019 in elderly patients: characteristics and prognostic factors based on 4-week follow-up. Journal of Infection .

Wang, M., Cao, R., Zhang, L., Yang, X., Liu, J., Xu, M., Shi, Z., Hu, Z., Zhong, W. and Xiao, G. (2020b) Remdesivir and chloroquine effectively inhibit the recently emerged novel coronavirus (2019-nCoV) in vitro. Cell Research 30 (3), 269-271.

Welsh, E. J., Bara, A., Barley, E. and Cates, C. J. (2010) Caffeine for asthma. Cochrane Database of Systematic Reviews (1).

Wen, W. X., Lee, S. Y., Siang, R. and Koh, R. Y. J. A. i. t. (2017) Repurposing pentoxifylline for the treatment of fibrosis: an overview. 34 (6), 1245-1269. 
Whitfield, K., Rambaldi, A., Wetterslev, J. and Gluud, C. (2009) Pentoxifylline for alcoholic hepatitis. Cochrane database of systematic reviews (4).

Wu, D., Yang, X. O. J. J. o. M., Immunology and Infection (2020a) TH17 responses in cytokine storm of COVID-19: An emerging target of JAK2 inhibitor Fedratinib.

Wu, J., Yan, Z., Schwartz, D. E., Yu, J., Malik, A. B. and Hu, G. J. T. J. o. I. (2013) Activation of NLRP3 inflammasome in alveolar macrophages contributes to mechanical stretch-induced lung inflammation and injury. 190 (7), 3590-3599.

Wu, Y., Xu, X., Chen, Z., Duan, J., Hashimoto, K., Yang, L., Liu, C. and Yang, C. (2020b) Nervous system involvement after infection with COVID-19 and other coronaviruses.Brain, Behavior, and Immunity .

Xu, X., Han, M., Li, T., Sun, W., Wang, D., Fu, B., Zhou, Y., Zheng, X., Yang, Y., Li, X., Zhang, X., Pan, A. and Wei, H. (2020) Effective treatment of severe COVID-19 patients with tocilizumab. Proceedings of the National Academy of Sciences , 202005615.

Yamazaki, Z. and Tagaya, I. J. J. o. G. V. (1980) Antiviral effects of atropine and caffeine. 50 (2), 429-431.

Yang, C.-Y., Chen, C.-S., Yiang, G.-T., Cheng, Y.-L., Yong, S.-B., Wu, M.-Y. and Li, C.-J. (2018) New insights into the immune molecular regulation of the pathogenesis of acute Respiratory Distress Syndrome. International journal of molecular sciences 19 (2), 588.

Yang, R.-Z., Lee, M.-J., Hu, H., Pollin, T. I., Ryan, A. S., Nicklas, B. J., Snitker, S., Horenstein, R. B., Hull, K. and Goldberg, N. H. J. P. m. (2006) Acute-phase serum amyloid A: an inflammatory adipokine and potential link between obesity and its metabolic complications. 3 (6).

Ye, M., Ren, Y. and Lv, T. (2020) Encephalitis as a clinical manifestation of COVID-19. Brain, Behavior, and Immunity .

Zhao, W., Ma, L., Cai, C. and Gong, X. J. I. j. o. b. s. (2019) Caffeine inhibits NLRP3 inflammasome activation by suppressing MAPK/NF- $x \mathrm{~B}$ and A2aR signaling in LPS-Induced THP-1 macrophages. 15 (8), 1571.

Zhu, N., Zhang, D., Wang, W., Li, X., Yang, B., Song, J., Zhao, X., Huang, B., Shi, W. and Lu, R. (2020) A novel coronavirus from patients with pneumonia in China, 2019. New England Journal of Medicine .

Zito, P. M. and Murgia III, R. D. (2018) Pentoxifylline (Trental) in Venous Insufficiency and Venous Leg Ulcers. Journal of the Dermatology Nurses' Association 10 (6), 294-296.

Zumla, A., Chan, J. F., Azhar, E. I., Hui, D. S. and Yuen, K. Y. (2016) Coronaviruses - drug discovery and therapeutic options. Nat Rev Drug Discov 15 (5), 327-47. 

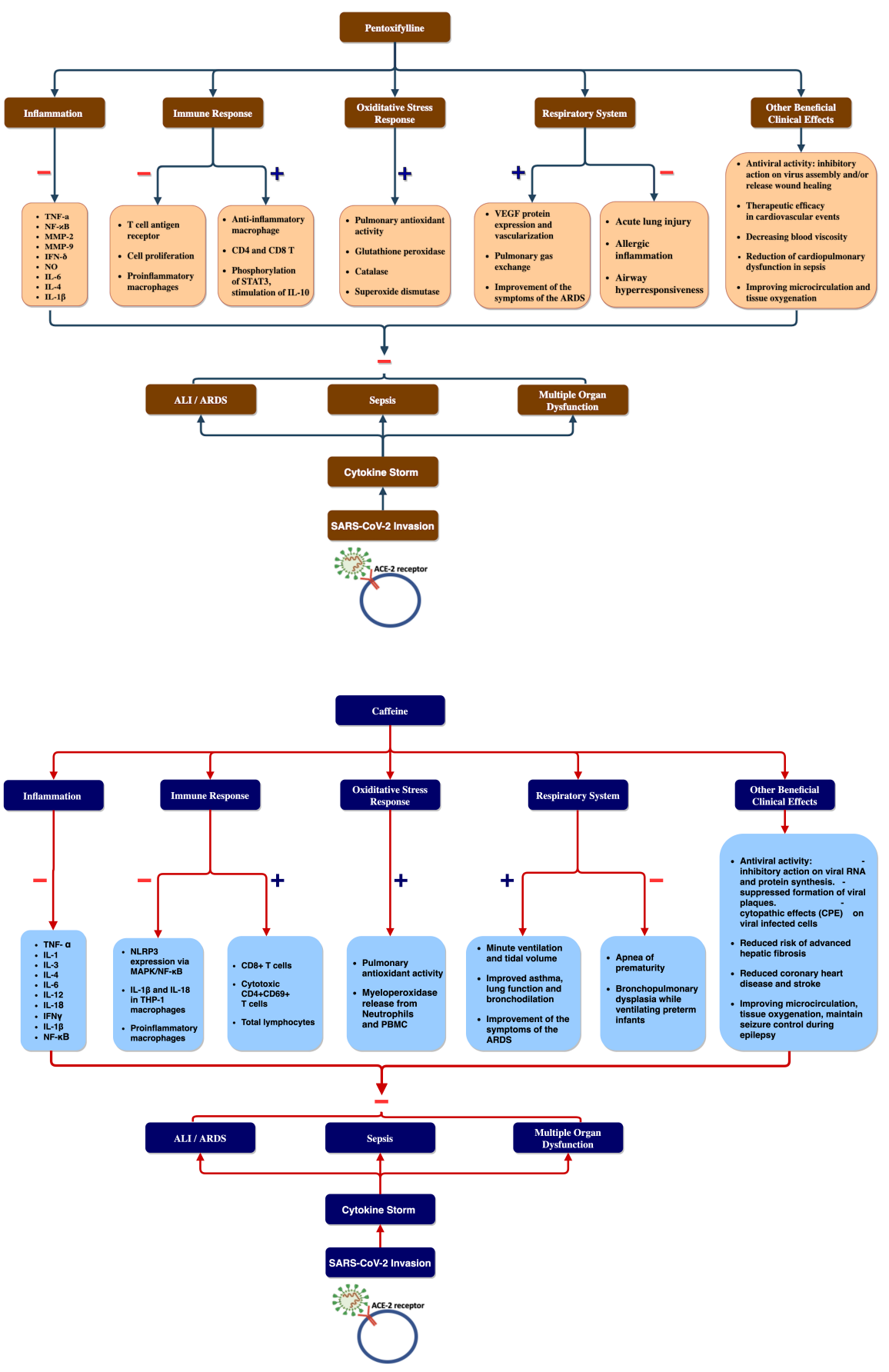